\title{
Capsule Commentary on Gordon et al., The Impact of Medicaid Expansion on Continuous Enrollment: a Two-State Analysis
}

\author{
Erin Brantley, MPH \\ Milken Institute School of Public Health, George Washington University, Washington, DC, USA.
}

J Gen Intern Med 34(9):1853

DOI: $10.1007 / \mathrm{s} 11606-019-05168-3$

(c) Society of General Internal Medicine 2019

$\mathrm{G}$ ordon and coauthors ${ }^{1}$ found that by expanding Medicaid under the Affordable Care Act (ACA), Colorado improved health insurance continuity for adults already enrolled in Medicaid. The cohort-Medicaid beneficiaries who were either pregnant, disabled, or low-income parents in 2013 - gained an average of one month per year of Medicaid enrollment and had a reduced chance of disenrollment in 2014 2015. The study compared Colorado's experience with neighboring Utah, which had not expanded at the time of the study, using difference-in-difference methods. Although the study is limited to two states, the findings are important given limited evidence so far on continuity of coverage under the ACA.

The authors used All Payer Claims Databases (APCDs) from the two states, an unusual data source for comparing state policies. The APCDs provided visibility into individuals' movement into and out of Medicaid over time. Unfortunately, the promise of APCDs for research was constrained when the Supreme Court decided states cannot require many employersponsored plans to participate. ${ }^{2}$ Because of this decision, the study cannot determine whether those leaving Medicaid gained employer-sponsored insurance or became uninsured.

Some policymakers have expressed concern that expanding Medicaid under the ACA might harm traditionally eligible beneficiaries. Gordon and coauthors find instead that previously eligible Medicaid recipients benefited from improved coverage continuity under expansion. There has been little research so far assessing impacts of expansion on traditionally eligible groups specifically, although one report found that waiting lists for people with disabilities to receive Home and Community Based Services grew more often in nonexpansion states than in expansion states. ${ }^{3}$

Published online July 9, 2019
The study highlights the fact that expansion and traditional beneficiaries are separate groups of people only when viewed at one point in time. Enrollees eligible under traditional criteria in 2013 might become expansion enrollees in 2014. Fluctuation between traditional and expansion eligibility occurs due to income changes and life events like childbirth, marriage or divorce, or a child turning 19. The study complements prior research finding that in the context of generous Medicaid eligibility for pregnant women, expanding Medicaid for nonpregnant adults improves prenatal care ${ }^{4}$ and disparities in preterm birth. ${ }^{5}$

Corresponding Author: Erin Brantley, MPH; Milken Institute School of Public Health George Washington University, Washington, DC, USA (e-mail: ebrantley@gwu.edu).

\section{Compliance with Ethical Standards:}

Conflict of Interest: The author declares that she does not have a conflict of interest.

\section{REFERENCES}

1. Gordon SH, Sommers BD, Wilson I, Galarraga O, Trivedi AN. The impact of Medicaid expansion on continuous enrollment: a two-state analysis. J Gen Intern Med. https://doi.org/10.1007/s11606-019-05101-8

2. Curfman G. All-Payer Claims Databases After Gobeille. Health Affairs Blog. 2017. Available from: https://www.healthaffairs.org/do/10.1377/ hblog20170303.058995/full/\#. Accessed 11 June 2019.

3. Musumeci M, Chidambaram P, O'Malley Watts M. Key Questions About Medicaid Home and Community-Based Services Waiver Waiting Lists. The Henry J. Kaiser Family Foundation. 2019. Available from: https://www. kff.org/medicaid/issue-brief/key-questions-about-medicaid-home-andcommunity-based-services-waiver-waiting-lists. Accessed 11 June 2019.

4. Wherry LR. State Medicaid expansions for parents led to increased coverage and prenatal care utilization among pregnant mothers. Health Services Research. 2018;53(5):3569-91.

5. Brown CC, Moore JE, Felix HC, Stewart MK, Bird TM, Lowery CL, et al. Association of state Medicaid expansion status with low birth weight and preterm birth. JAMA. 2019;321(16):1598-609.

Publisher's Note Springer Nature remains neutral with regard to jurisdictional claims in published maps and institutional affiliations. 